\title{
Phonological processing in students with developmental dyslexia, ADHD and intellectual disability
}

\author{
Ana Beatriz Leite dos Anjos' \\ https://orcid.org/0000-0002-1905-6165 \\ Alexandre Lucas de Araújo Barbosa ${ }^{2}$ \\ https://orcid.org/0000-0003-1493-3429 \\ Cíntia Alves Salgado Azoni ${ }^{3}$ \\ https://orcid.org/0000-0003-2175-9676
}

Universidade Federal do Rio Grande do Norte - UFRN, Curso de Graduação em Fonoaudiologia, Natal, Rio Grande do Norte, Brasil.

Universidade Federal do Rio Grande do Norte - UFRN, Programa de Pós-graduação (Mestrado) em Fonoaudiologia, Natal, Rio Grande do Norte, Brasil.

Universidade Federal do Rio Grande do Norte - UFRN, Departamento de Fonoaudiologia, Natal, Rio Grande do Norte, Brasil.

Project carried out at the Departamento de Fonoaudiologia da Universidade Federal do Rio Grande do Norte - UFRN, Natal, Rio Grande do Norte, Brasil.

Research support source: ABCD Institute

Conflict of interests: Nonexistent

\section{(c) (i)}

Received on: April 15, 2019

Accepted on: September 30, 2019

Corresponding address:

Ana Beatriz Leite dos Anjos

Rua Coronel Auris Coelho, 897, Nova

Descoberta

59075-400 - Natal, Rio Grande do Norte, Brasil

E-mail:leiteanjos7@gmail.com

\section{ABSTRACT}

Purpose: to compare the performance of students with dyslexia, intellectual disability and ADHD on the skills of phonological awareness, phonological access to the mental lexicon, and phonological working memory.

Methods: this is a descriptive, cross sectional and quantitative study. The sample was composed of 32 students, divided into the following groups: G1 - students with dyslexia; G2 - students with ADHD; G3 - students with intellectual disability. The children were assessed on their skills of phonological awareness, phonological working memory, and phonological access to the mental lexicon. A descriptive and inferential analysis was made, using the non-parametric Kruskal-Wallis test.

Results: statistically significant differences were observed among the three groups on the phonological working memory skills for pseudowords, forward digit repetition, and backward digit repetition; phonological awareness on syllable level, phoneme level, test total score, and digits subtest of the rapid automatized naming test. Through the descriptive analysis, it was observed that G1 had the best results on all the skills assessed, followed by G2 and G3.

Conclusion: differences were found on the skills of phonological working memory and phonological awareness among the groups of students presented with dyslexia, ADHD and intellectual disability.

Keywords: Reading; Differential Diagnosis; Neurodevelopmental Disorders; Child 


\section{INTRODUCTION}

Phonological processing refers to the process of using phonological information when oral and written language is employed, with the involvement of the skills of phonological awareness, quick access to the mental lexicon, and phonological working memory. These skills are directly related to the written language development ${ }^{1}$.

Phonological awareness is the ability to understand and control the sound aspects of the language. This ability makes learning the relation grapheme-phoneme easier ${ }^{1}$. Phonological access to the mental lexicon is the ability to access the sound information referring to a visual stimulus ${ }^{1}$. It is important in decoding, fluency and understanding of reading. Children with reading difficulties tend to present low performance in tasks involving rapid automatized naming ${ }^{2}$. Lastly, phonological working memory is the ability to store and recover sound information. It is related to development in reading, specifically the reading comprehension ability ${ }^{3}$.

The difficulties in the process of written language development may occur due to various factors, such as environmental or biological ones ${ }^{4}$. According to the literature, conditions such as developmental dyslexia ${ }^{5}$, attention-deficit/hyperactivity disorder - $A D H D^{6}$ and intellectual disability ${ }^{7}$ may present significant difficulties in predictive abilities of reading.

Dyslexia is a specific learning disorder which impairs reading $^{8}$, involving deficits in phonological processing ${ }^{9}$, as well as difficulties and slow processing in other linguistic abilities ${ }^{10}$.

The attention-deficit/hyperactivity disorder is characterized by persistent patterns of inattention, hyperactivity/impulsiveness and/or a combination of both ${ }^{8}$. Children with such condition may present difficulties in reading as a secondary alteration to the initial diagnosis, mainly attributed to the attentional deficit ${ }^{11}$, showing alterations in attentional demands, self-regulation and phonological processing.

As for Intellectual disability, it is defined by difficulties in intellectual and adaptive functions, with early beginning in development ${ }^{8}$. The difficulties in reading, as well as in recognizing letters and having reading fluency ${ }^{12,13}$, may be a consequence of alterations in oral language development ${ }^{14}$.

In spite of the heterogeneous character of the neurodevelopmental disorders, the evaluator may find it difficult to distinguish them, since the signs and symptoms can be present in more than one diagnosis.
For instance, children with ADHD and dyslexia can present inattention symptoms for different etiologic factors ${ }^{15,16}$.

Knowledge about the different characteristics of the phonological processing for reading development in the various neurodevelopmental disorders must be attained $^{4}$, as the differential diagnosis is essential to define effective interventions and prognostic outlining. Thus, the objective of this paper was to compare the performance of students diagnosed with dyslexia, intellectual disability and ADHD on the skills of phonological awareness, phonological access to the mental lexicon, and phonological working memory. This study aimed to answer the following question: Are there differences in the phonological processing performance among the conditions of developmental dyslexia, ADHD and intellectual disability?

\section{METHODS}

This is a descriptive, cross-sectional, quantitative study, approved by the Ethics Committee of the Hospital Universitário Onofre Lopes - Universidade Federal do Rio Grande do Norte, under the no. 1.012.635. All the patients signed the Informed Consent Form (ICF) and/ or the Informed Assent Form (IAF).

Children and adolescents in the age range from 6 to 16 years old of both genders were included. They were from public and private schools from the capital and metropolitan area where the study took place, and attended a research project of the abovementioned university. The participants were chosen based on the initial complaint of learning difficulties and interdisciplinary assessment of the following professionals for the different conditions: children with the inattentive and combined subtypes of ADHD were referred by a neuropediatrician or child psychiatrist, and were submitted to neuropsychological evaluation; and, the children with ID and developmental dyslexia, by a psychologist/neuropsychologist. Hence, in addition to these professionals, the phonological evaluation was performed, as described in this study, along with the collection of anamnesis data and the case discussion. The diagnoses were defined according to the criteria established in the Diagnostic and Statistical Manual of Mental Disorders (DSM-V) ${ }^{8}$.

The sample was included by convenience, as the demand was directed to the research project. A total of 32 children participated, 11 (34.37\%) females and 21 (65.63\%) males, averaging 9.84 years old $(S D=2.42)$, subdivided into the following groups: 
- Group 1 - G1: 14 students with developmental dyslexia, without previous speech-language-hearing intervention;

- Group 2 - G2: seven students with ADHD, with complaints of difficulties at school, not using medication during assessment;

- Group 3 - G3: 11studentswith intellectual disability, with complaints of difficulties at school, without the degree of impairment being specified.

The evaluations were carried out in three 60-minute long individual sessions. Although some instruments used are meant for the younger age group of students, these were chosen due to the lack of national instruments for adolescents and, especially, because of their schooling, since even the 16-year-old participants were either attending fourth grade or presented an inferior performance caused by their initial complaints. The following skills of the phonological processing were taken into account, with the use of the respective protocols:

- Phonological awareness - Instrument of Sequential Assessment - CONFIAS ${ }^{17}$ : it evaluates the metalinguistic ability to reflect and manipulate the language sounds. It is divided into syllabic and phonemic levels, with maximum score of 40 and 30 points, respectively. The Syllable (S) Level activities are: synthesis, segmentation, syllable identification, rhyme identification, word production with a given syllable, medial syllable identification, rhyme production, exclusion, and transposition. Phonemic (P) Level: word production beginning with given sound, initial phoneme identification, final phoneme identification, exclusion, synthesis, segmentation and transposition.
- Phonological working memory - Phonological Working Memory Test - Nonwords and Digits ${ }^{18}$ : it involves pseudowords repetition, and forward and backward digit repetition. The nonwords test is based on the phonological structure of the language, containing 40 made-up words with phonemes from Portuguese (fricatives, nasals, occlusives, liquids, and closed vowels) in sequences of two to five syllables, with maximum score of 80 . The digit activity consists of forward number sequences from one to nine (sequences from two to eight digits), and backward ones (sequences from two to seven digits), with maximum score of 28 and 24 , respectively.

- Phonological access to the mental lexicon - Rapid Automatized Naming Test - RAN ${ }^{19}$ : it evaluates the phonological access to the mental lexicon, in which the person must quickly and sequentially name visual stimuli in the categories of objects, colors, letters and digits. The results are expressed in seconds.

An inferential and descriptive analysis was performed. The non-parametric Kruskal-Wallistest was used, considering the confidence interval of $95 \%$ and the significance level of 0.05 . The data were charted and analyzed using the statistical software IBM ${ }^{\circledR}$ SPSS Statistics version 23.

\section{RESULTS}

The students diagnosed with developmental dyslexia obtained the best results in the skills of phonological awareness (Tables 1 and 2), rapid automatized naming (Table 3), and phonological working memory (Table 4), followed by the students with ADHD and ID.

Table 1. Performance of the groups on the tasks of phonological awareness, at the syllabic level

\begin{tabular}{cccccccccc}
\hline & S1 & S2 & S3 & S4 & S5 & S6 & S7 & S8 & S9 \\
\cline { 2 - 10 } G1 & $3.39 \pm 0.07$ & $3.93 \pm 0.07$ & $3.36 \pm 0.19$ & $3.07 \pm 0.19$ & $3.64 \pm 0.16$ & $2.57 \pm 0.34$ & $1.29 \pm 0.32$ & $4.50 \pm 0.76$ & $2.86 \pm 0.40$ \\
G2 & $4.00 \pm 0.00$ & $4.00 \pm 0.00$ & $3.14 \pm 0.26$ & $2.29 \pm 0.47$ & $3.71 \pm 0.18$ & $2.29 \pm 0.52$ & $1.00 \pm 0.53$ & $3.57 \pm 1.15$ & $2.29 \pm 0.64$ \\
G3 & $3.30 \pm 0.39$ & $3.70 \pm 0.21$ & $2.00 \pm 0.44$ & $2.50 \pm 0.40$ & $3.10 \pm 0.40$ & $1.50 \pm 0.30$ & $0.50 \pm 0.30$ & $1.70 \pm 0.53$ & $0.90 \pm 0.40$ \\
\hline
\end{tabular}

Legend: G1 = developmental dyslexia; G2 = ADHD; G3 = intellectual disability; SD = standard deviation; S = phonological awareness test, syllabic level 
Table 2. Performance of the groups on the tasks of phonological awareness, at the phonemic level

\begin{tabular}{cccccccc}
\hline & F1 & F2 & F3 & F4 & F5 & F6 & F7 \\
\hline \multicolumn{7}{c}{ average \pm SD } \\
G1 & $2.93 \pm 0.30$ & $2.57 \pm 0.27$ & $2.50 \pm 0.35$ & $1.71 \pm 0.39$ & $2.21 \pm 0.35$ & $1.14 \pm 0.40$ & $0.71 \pm 0.24$ \\
G3 & $1.86 \pm 0.76$ & $3.57 \pm 2.10$ & $1.57 \pm 0.48$ & $0.57 \pm 0.29$ & $1.14 \pm 0.34$ & $0.43 \pm 0.42$ & $1.14 \pm 0.63$ \\
G3 & $1.70 \pm 0.39$ & $2.00 \pm 0.47$ & $0.80 \pm 0.20$ & $0.50 \pm 0.22$ & $1.20 \pm 0.35$ & $0.71 \pm 0.24$ & $1.14 \pm 0.34$ \\
\hline
\end{tabular}

Legend: $\mathrm{G} 1$ = developmental dyslexia; G2 = ADHD; G3 = intellectual disability; SD = standard deviation; P = phonological awareness test, phonemic level

Table 3. Performance of the groups on the tasks of rapid automatized naming

\begin{tabular}{cccccccc}
\hline \multirow{2}{*}{ Variables } & \multicolumn{2}{c}{ G1 } & \multicolumn{2}{c}{ G2 } & \multicolumn{2}{c}{ G3 } \\
\cline { 2 - 7 } & Average & SD & Average & SD & Average & SD \\
\hline Digits & 48.54 & 16.95 & 73.00 & 29.40 & 69.40 & 30.95 \\
Letters & 47.85 & 17.29 & 55.83 & 30.54 & 67.10 & 22.48 \\
Objects & 61.23 & 9.78 & 66.83 & 17.52 & 72.50 & 18.47 \\
Colors & 60.31 & 16.55 & 76.17 & 23.69 & 100.90 & 66.01 \\
\hline
\end{tabular}

Legend: $\mathrm{G1}$ = developmental dyslexia; G2 = ADHD; G3 = intellectual disability; SD = standard deviation

Table 4. Performance of the groups on the tasks of phonological working memory

\begin{tabular}{ccccccc}
\hline \multirow{2}{*}{ Variables } & \multicolumn{2}{c}{ G1 } & \multicolumn{2}{c}{ G2 } & \multicolumn{2}{c}{ G3 } \\
\cline { 2 - 7 } & Average & SD & Average & SD & Average & SD \\
\hline Pseudowords & 53.23 & 8.51 & 56.67 & 14.94 & 29.90 & 15.38 \\
Forward digit repetition & 15.46 & 4.85 & 14.67 & 3.44 & 10.20 & 3.61 \\
Backward digit repetition & 6.85 & 4.27 & 6.50 & 3.20 & 2.90 & 4.33 \\
\hline
\end{tabular}

Legend: G1 = developmental dyslexia; G2 = ADHD; G3 = intellectual disability; SD = standard deviation

Statistically significant differences were observed in the skills of total phonological working memory of pseudowords $(p=0.00)$, forward digit repetition $(p=$ $0.01)$, and backward digit repetition $(p=0.01)$; phonological awareness on the syllable level $(p=0.00)$, phoneme level $(p=0.04)$, and test total $(p=0.00)$, in addition to the digit subtest of the rapid automatized naming $(p=0.05)$. The group with dyslexia obtained the best performance, followed by ADHD and, at last, intellectual disability.

Table 5 presents the results of the comparison in pairs of groups.

Table 5. Comparison of the groups in pairs

\begin{tabular}{cccc}
\hline \multirow{2}{*}{ Variables } & $\mathbf{G 1} \mathbf{x ~ G 2}$ & $\mathbf{G 1} \mathbf{x} \mathbf{G 3}$ & $\mathbf{G} \mathbf{x} \mathbf{G 3}$ \\
\cline { 2 - 4 } & $\mathbf{p}$ & $\mathbf{p}$ & $\mathbf{p}$ \\
PA-S & 0.33 & $<0.01^{*}$ & 0.12 \\
PA-P & $0.07^{*}$ & $<0.01^{*}$ & 0.41 \\
RAN Digits & 0.31 & $0.05^{*}$ & 0.92 \\
RAN Letters & 0.45 & 0.08 & 0.58 \\
RAN Objects & 0.29 & 0.07 & 0.61 \\
RAN Colors & 0.10 & $0.02^{*}$ & 0.82 \\
PWM-P & 0.82 & $<0.01^{*}$ & $0.01^{*}$ \\
PWM-FD & 0.82 & $0.01^{*}$ & 0.10 \\
PWM-BD & 0.88 & $0.01^{*}$ & $0.05^{*}$ \\
\hline
\end{tabular}

Legend: G1 = developmental dyslexia; G2 = ADHD; G3 = intellectual disability; PA-S = phonological awareness, syllabic level; PA-P = phonological awareness, phonemic level; RAN = rapid automatized naming; PWM-P = phonological working memory pseudowords; PWM-FD = phonological working memory, forward digit repetition; $\mathrm{PWM}-\mathrm{BD}=$ phonological working memory, backward digit repetition; ${ }^{*}=$ statistically significant value by the Kruskal-Wallis test 


\section{DISCUSSION}

This paper aimed at comparing the performance of individuals with developmental dyslexia, ADHD and ID in tasks of phonological awareness, phonological working memory, and phonological access to the mental lexicon.

Differences were observed in the phonological working memory and the phonological awareness tests between the three groups. Hence, it is noted that the phonological processing may differ in the neurodevelopmental disorders with distinct etiologies $7,11,19,20$. This may be due to the different cognitive profiles of the conditions, reinforcing that they refer to different disorders ${ }^{5,6,11,14}$. The difficulties in abilities composing the phonological processing may justify the alterations in reading of these different conditions, as the phonological working memory ${ }^{21}$ and the phonological awareness $^{22}$ interfere significantly with the processes of learning to read. These results agree with the previous studies, demonstrating that children with these conditions present worse performance in this type of task, when compared to typically developed individuals ${ }^{6,10,23}$.

In ADHD, the alterations in executive and attentional functions are primary, which generate academic difficulties $^{20}$; whereas, in intellectual disability, these are originated by delays in oral language development, which mainly causes difficulties in reading comprehension ${ }^{14}$. Finally, in dyslexia, the primary deficit is in phonological processing skills ${ }^{10}$, even though some studies already describe alterations in executive functions as secondary to these alterations ${ }^{16}$.

Based on the descriptive analyses, it is possible to observe that the subjects with dyslexia obtained the best results in all the tests, although with worse performance in the pseudowords subtest if compared to the children with ADHD. This may happen because, despite the phonological deficits being persistent in dyslexia, there are important differences between this condition, ADHD and intellectual disability. It is observed that, in ADHD and in intellectual disability, there is impairment of other cognitive functions, such as the executive functions ${ }^{24,25}$ and reasoning ${ }^{26,27}$, which may have more complex consequences on specific abilities, though this is not necessarily the case in all the children with dyslexia ${ }^{28}$.

In reference more specifically to ADHD, a great part of the children with such diagnosis present impaired performance in written language. The difficulty in reading and writing is caused by problems of visual integration, motor coordination, working memory, organization and planning ${ }^{29}$.

The difference in phonological awareness performance was observed between the groups, with better performance of the individuals with dyslexia, followed by ADHD and intellectual disability, respectively. Nevertheless, the origin of these difficulties differs. In dyslexia, the deficit in phonological awareness is the origin of the reading problems, causing the graphemephoneme relating process to have failures ${ }^{30}$. In ADHD, the lack of attention prevents important information for development of metalinguistic abilities to be retained ${ }^{6}$. Lastly, in intellectual disability, phonological awareness is an ability significantly affected, especially in rhyme detection and phonemic manipulation, due to failures in short-term phonological memory ${ }^{31}$.

In the working memory test, which evaluates phonological working memory involving pseudowords and digits, the group of children with ID (G3) presented the worst performance of the three, which agrees with the characteristics of the condition. Although in children with ADHD this ability is impaired, intellectual disability has verbal comprehension, quantitative reasoning and cognitive efficiency also affected ${ }^{8}$, influencing the results, as the test requires these abilities as well, since the child must verbally repeat what is said by the evaluator. Among the cognitive alterations of the individuals with intellectual disability, there are planning, reasoning, verbal comprehension, problemsolving, working memory, quantitative reasoning, and cognitive efficiency ${ }^{8}$.

The G2 obtained worse performance in the digit test if compared to the pseudowords test. This subtest demands cognitive resources, such as strategic planning and decision making, which are directly related to attention control, whose ability has deficits in children with $\mathrm{ADHD}^{6,32}$.

No difference was observed between the groups in the letter, colors and objects subtests of the rapid automatized naming. This result is in agreement with a research in Brazilian children with dyslexia and ADHD. The difficulty in phonological access to the mental lexicon impairs the relation between naming and automatization of stimuli, thus, affecting the development of reading and writing ${ }^{33}$.

This study brings relevant contributions to the Brazilian scientific and clinical situation, since it presents the differences in reading predictive skills in groups with diagnosis in which speech-languagehearing has a relevant practice. The need of knowledge 
regarding the different manifestations of phonological processing in the neurodevelopmental disorders is highlighted, in order to achieve better therapeutic and prognostic outlining. Furthermore, the need of interdisciplinary practice for the diagnosis of alterations in written language development is highlighted, as well as a greater number of subjects with the different conditions so as to outline their linguistic profiles.

This study is limited concerning the use of protocols not specific for the age group of up to 16 years old, as a consequence of there being a reduced amount of instruments for the assessment of reading-related skills in Brazil.

\section{CONCLUSION}

Differences were found among the groups with dyslexia, ADHD and intellectual disability in the skills of phonological working memory, phonological awareness, and in the digit subtest of the rapid automatized naming, with better performance for those with dyslexia, followed by ADHD and intellectual disability.

\section{ACKNOWLEDGEMENT}

Gratitude is extended to the Instituto ABCD, for the support given to the Laboratório de Linguagem Escrita, Interdisciplinaridade e Aprendizagem (Laboratório LEIA).

\section{REFERENCES}

1. Wagner RK, Torgesen JK. The nature of phonological processing and its causal role in the acquisition of reading skills. Psychol Bull. 1987;101(2):192-212.

2. Capellini SA, Ferreira TL, Salgado CA, Ciasca SM. Performance of good readers, students with dyslexia and attention deficit hyperactivity disorder in rapid automatized naming. Rev Soc Bras Fonoaudiol. 2007;12(2):114-9.

3. Piccolo LR, Salles JF. Vocabulário e memória de trabalho predizem desempenho em leitura de crianças. Revista Psicologia: Teoria e Prática. 2013;15(2):180-91.

4. Azoni CAS. Diagnóstico diferencial dos transtornos da linguagem escrita. In: Lamônica DA, Britto DB (orgs). Tratado de Linguagem: perspectivas contemporâneas. 1.ed.São Paulo: BookToy; 2016. p. 165-73.

5. Navas AL, Ferraz C, Borges JP. Phonological processing deficits as a universal model for dyslexia: evidence from orthographies. Codas. 2014;26(6):509-19.

6. Gonçalves-Guedim TF, Capelatto IV, SalgadoAzoni CA, Ciasca SM, Crenitte PAP. Performance of children with attention deficit hyperactivity disorder in phonological processing, reading and writing. Rev. CEFAC. 2017;19(2):242-52.

7. Dessemontet RS, Chambrier EF, Martinet C, Moser $\mathrm{U}$, Bayer N. Exploring phonological awareness skills in children with intellectual disability. Am J Intellect Dev Disabil. 2017;122(6):476-91.

8. American Psychiatry Association. Manual Diagnóstico e Estatístico dos Transtornos Mentais. 5a ed. Porto Alegre: Artmed; 2014.

9. Mendes GG. Processamento fonológico e habilidades de leitura e de escrita em crianças em processo de alfabetização. [Dissertação] Ribeirão Preto (SP): Universidade de São Paulo; 2015.

10. Peterson RL, Pennington BF. Developmental dyslexia. Annu Rev Clin Psychol. 2015;11(1):283-307.

11. Cunha VL, Silva C, Lourencetti MD, Padula NA, Capellini SA. Performance of students with attention deficit disorder and hyperactivity in metalinguistic and reading tasks. Rev. CEFAC. 2013;15(1):40-50.

12. Hill D. Phonics based reading interventions for students with intellectual disability: a sistematic review. Journal of Education and Training Studies. 2016;4(5):205-14.

13. Merimee SN. Addressing reading fluency of student with intellectual disabilities using a mutiple probe design. Kentucky Teacher Educational Journal: The Journal of the Teacher Education Division of the Kentucky Council for Exceptional Children. 2017;4(1): article 3.

14. Wingerden E, Segers E, Balkom H, Verhoeven L. Cognitive and linguistic predictors of reading comprehension in children with intellectual disability. Research in Developmental Disabilities. 2014;35(11):3139-47.

15. Santos LF, Vasconcelos L. Transtorno de déficit de atenção e hiperatividade em crianças: uma revisão interdisciplinar. Psicologia: Teoria e Prática. 2010;26(4):717-24.

16. Lima RF, Azoni CAS, Ciasca SM. Attentional performance and executive functions in children with learning difficulties. Psicologia: Teoria e Prática. 2011;24(4):685-91.

17. Moojen S, Lamprecht R, Santos RM, Freitas GM, Brodacz R, Siqueira M et al. CONFIAS Consciência 
Fonológica: Instrumento de Avaliação Sequencial. São Paulo: Casa do Psicólogo; 2003.

18. Grivol MA, Hage SRV. Memória de trabalho fonológica: estudo comparativo entre as faixas etárias. J Soc Bras Fonoaudiol. 2011;23(3):245-51.

19. Ferreira TL, Capellini SA, Ciasca SM, Tonelotto JMF. Desempenho de escolares leitores proficientes no teste de nomeação automatizada rápida - RAN. Temas Sobre Desenvolvimento. 2003;12(69):26-32.

20. Toledo MM, Lima RF, Simão AP, Ribeiro MV. Atenção. In: Ciasca SM, Rodrigues SD, Azoni CAS, Lima RF (orgs). Transtornos de aprendizagem neurociência e interdisciplinaridade. São Paulo: Booktoy; 2015. p.53-66.

21. Nicolielo-Carrilho AP, Crenitte PAP, LopesHerrera SA, Hage SR de V. Relationship between phonological working memory, metacognitive skills and reading comprehension in children with learning disabilities. Journal of Applied Oral Science. 2018;26.

22. Saiegh-Haddad E, Taha $H$. The role of morphological and phonological awareness in the early development of word spelling and reading in tipically developing and disabled arabic readers. Dyslexia. 2017;23(4):345-71.

23. Soltani A, Roslan S. Contributions of phonological awareness, phonological short-term memory, and rapid automated naming, toward decoding ability in students with mild intellectual disability. Res Dev Disabil. 2013;34(3):1090-9.

24. Chiang HL, Gau SS. Impact of executive functions on school and peer functions in youths with ADHD. Res Dev Disabil. 2014;35(5):963-72.

25. Memisevic $\mathrm{H}$, Sinanovic $\mathrm{O}$. Executive function in children with intellectual disability - the effects of sex, level and a etiology of intellectual disability. J Intellect Disabil Res. 2014;58(9):830-7.

26. Greenspan S, Woods G. Intellectual disability as a disorder of reasoning and judgement: the gradual move away from intelligence quotient-ceilings. Curr Opin Psychiatry. 2014;27(2):110-6.

27. Tamm L, Juranek J. Fluid reasoning deficits in children with ADHD: evidence from fMRI. Brain Res. 2012;1465:48-56.

28. Medina GBK, Minetto MFJ, Guimarães SRK. Funções executivas na dislexia do desenvolvimento: revendo evidências de pesquisas. Rev. Bras. Ed. Esp. 2017;23(3):439-54.

29. Silva D, Colvin L, Glauert R, Stanley F, Jois RS, Bower C. Literacy and numeracy underachievement in boys and girls with ADHD. J Atten Disord. 2015;pii:1087054715596575.

30. Stein J. What is developmental dyslexia? Brain Sciences. 2018;8(2):26.

31. Sermier Dessemontet $R$, de Chambrier AF, Martinet $\mathrm{C}$, Moser $\mathrm{U}$, Bayer $\mathrm{N}$. Exploring phonological awareness skills in children with intellectual disability. Am J Intellect Dev Disabil. 2017;122(6):476-91.

32. Messina LF, Tiedemann KB. Avaliação da memória de trabalho em crianças com transtornos do déficit de atenção e hiperatividade. Psicologia USP. 2009;20(2):209-28.

33. Alves LM, Siqueira CM, Ferreira MCM, Alves JFM, Lodi DF, Bicalho $L$ et al. Rapid naming in brazilian students with dyslexia and attention deficit hyperactivity disorder. Frontiers in Psychology. 2016;7:21. 